\title{
Neoliberalismo e horizontes da precarização do trabalho
}

\author{
José Newton Garcia de Araújo ${ }^{1}$ \\ Pontifícia Universidade Católica de Minas Gerais (Belo Horizonte, MG, Brasil)
}

Este texto discute, inicialmente, a precarização do trabalho no atual cenário do neoliberalismo. Baseado em pesquisa bibliográfica e documental, apresenta as bases teóricas e metodológicas da clássica psicossociologia francesa e seu desdobramento como psicossociologia do trabalho. Em seguida, buscamos ressituar esta disciplina nos campos do trabalho e da política, em uma articulação com os conceitos de precariado e de necropolítica. Evoca-se aqui a perda dos direitos trabalhistas e de cidadania, que desemboca na crescente desigualdade social e no "direito de morte" do Estado sobre as camadas mais pauperizadas da população. $\mathrm{O}$ texto interroga também as possibilidades da assistência pública à saúde dos trabalhadores, especialmente aqueles submetidos ao trabalho por aplicativos. A respeito dessa atividade, abordam-se os avanços políticos e as contradições inerentes ao cooperativismo de plataforma, em sua oposição ao capitalismo de plataforma.

Palavras-chave: Neoliberalismo, Psicossociologia do trabalho, Precariado, Necropolítica, Cooperativismo de plataforma.

Neoliberalism and horizons of work precariousness

This text discusses, initially, the precariousness of work in the current scenario of neoliberalism. Based on bibliographic and documentary research, it initially presents some theoretical and methodological bases of classical French psychosociology and its development as work psychosociology. Then, we seek to reposition this discipline in the fields of work and politics, through a possible articulation with the concepts of precariat and necropolitics. Here, we evoke the loss of labor and citizenship rights, which leads to growing social inequality and the "right of death", from the State, on the poorest segments of the population. The text also questions the possibilities of public health care for workers, especially those submitted to working with applications. Regarding this activity, political advances and contradictions inherent to platform cooperatives are addressed, in their opposition to platform capitalism.

Keywords: Neoliberalism, Psychosociology of work, Precariat, Necropolitics, Platform cooperativism.

\section{Introdução}

E ste texto se propõe a debater algumas questões relativas ao trabalho precário no atual contexto das políticas neoliberais. Inicialmente, lembro que as pesquisas relativas ao mundo do trabalho, no campo que aproxima as psicologias social, política e clínica, remetem a uma pluralidade de abordagens teóricas e metodológicas, incluídas as modalidades de pesquisa e intervenção nos ambientes de trabalho. É justamente pensando nas convergências entre essas abordagens que proponho algumas considerações pontuais sobre uma disciplina que abarca conexões diversas com a psicologia social do trabalho e com a psicologia política. Trata-se da psicossociologia do trabalho, tomando-a como parte das correntes francesas denominadas clínicas do trabalho, que incluem a psicodinâmica do trabalho (Dejours, 2012), a clínica da atividade (Clot, 2010) e a ergologia (Schwartz, 2012), todas elas com uma herança comum da ergonomia da atividade (Wisner, 1994).

Para discorrer sobre a psicossociologia do trabalho, é preciso situá-la como um desdobramento da clássica psicossociologia francesa, representada por nomes como Barus-Michel, Enriquez e Lévy (2002), Pagès (1987), Giust-Desprairies (2001), Amado e Enriquez (2011), além de outros autores conhecidos pelos estudiosos brasileiros da área. Por sua vez, a psicossociologia do trabalho, que tem em Lhuilier (2014) um nome de referência - e é a seus textos que recorro neste momento -

1 https://orcid.org/0000-0001-9648-9741 
estaria realinhada com o campo que Daniellou (2015) denominou "ergodisciplinas", aquelas que, na esteira da ergonomia da atividade, sustentam a premissa de que o trabalhar supõe gerir a distância entre o trabalho prescrito e o real - refiro-me às clínicas do trabalho.

Vale observar que a psicossociologia originalmente tem como premissa investigar não propriamente a "atividade de trabalho", mas as instâncias mais amplas que a envelopam, como as organizações, as instituições, grupos e comunidades. Nessas unidades sociológicas, ela se ocupa de questões como conflitos de poder, ou seja, as dimensões políticas e pulsionais das condutas individuais e coletivas, em que as estratégias supostamente racionais se cruzam com a irracionalidade dos sistemas de crenças, com as dimensões conscientes e inconscientes de nossas condutas e decisões, com a dialética entre forças instituintes e instituídas. Quero dizer, é a partir desse enquadre mais amplo que a psicossociologia do trabalho vai localizar a análise da atividade, ou seja, é na moldura organizacional e institucional que ela chega à atividade do trabalho.

Quanto às suas metodologias de intervenção, ela tem na pesquisa-ação de Lewin (1997) uma de suas inspirações de base, o que implica, grosso modo, a valorização do saber de todo sujeito, individual ou coletivo, de sua capacidade de analisar e transformar a realidade, nos espaços de vida e de trabalho. Tal abordagem tem ressonâncias - assimiláveis a uma pedagogia política da escuta nos trabalhos de Ivar Oddone (1977/2015), que privilegia a experiência ou o saber dos trabalhadores, além de sua inovadora proposta da Comunidade Centífica Ampliada. Foi ele também que criou a técnica da "instrução ao sósia", retomada por Yves Clot (2015), tendo ainda proximidades com o "Dispositivo dinâmico de três polos" da ergologia (Trinquet, 2010), ou ainda, com o espaço coletivo de discussão da psicodinâmica do trabalho (Martins \& Mendes, 2012).

Para Giust-Desprairies (2001), o caráter clínico da psicossociologia clássica se desvela quando atendemos a uma demanda concreta, em um contexto de sofrimento, interrogando a questão do sentido do trabalho, considerando o indivíduo e o grupo como interlocutores aptos a compreender as próprias dificuldades, ou seja, capazes de elaborar significações. Aqui, deve-se levar em conta que o problema do sentido é investigado na articulação entre as esferas psíquica e social, analisadas no contexto da atividade de trabalho.

Outro aspecto a salientar é que a dinâmica dos fenômenos coletivos, no interior das organizações e instituições, é permeada por experiências afetivas, conscientes e inconscientes, que impactam condutas e representações individuais e grupais, sempre articuladas a determinantes econômico-sociais e políticos. Daí a interação entre as dimensões subjetiva e objetiva, psíquica e social, interna e externa, que nos permitem evitar as dicotomias entre as esferas psicológica e sociológica na análise de um dado fenômeno (Gaulejac, 2001).

Ao mesmo tempo, a psicossociologia reserva um lugar especial para a análise da implicação do pesquisador ou do profissional, nos processos de intervenção. Para ela, a análise da implicação deve ser permanente, de modo que o pesquisador possa tomar distância de sua própria atuação, analisando o alcance e os riscos de suas contratransferências (Amado, 2002; Ben-Slama, 1999; Devereux, 1980). Com efeito, sem a análise dessa implicação, uma intervenção pode se desviar de seus objetivos. Em outras palavras, mergulhado na complexidade de uma situação coletiva ou institucional na qual intervém, o pesquisador se depara com o duplo risco: de um lado, pode misturar-se afetivamente ou politicamente às "causas" em jogo e nelas se perder; de outro, ao pretender manter-se ilusoriamente neutro, distante da situação ou das pessoas nela envolvidas, corre o risco de não captar a sua dramaticidade, as dimensões de angústia ou sofrimento desses sujeitos.

Os espaços de atuação da psicossociologia são múltiplos, como as organizações ligadas à educação, à saúde, às esferas jurídicas, à produção de bens e serviços, ONGs, prisões, sindicatos, comunidades etc., espaços que se movem não só em torno de jogos de poder, mas também em 
torno de processos coletivos de emancipação e mudança. Ora, toda organização tem de lidar, no dia a dia, com a questão da mudança e de sua gestão, ligada à discussão de seus objetivos e valores, às exigências de adaptação ou resistência a fenômenos políticos e sociais emergentes, com o próprio sentido de sua inserção na sociedade. Isso implica conflitos internos, em um embate permanente entre as forças instituídas, detentoras formais do poder, e as forças instituintes. $O$ tema da mudança remete, quase que imediatamente, ao seu correlato, que é a resistência, um conceito que merece ser discutido pelo fato de ser polissêmico e ambíguo, pois comporta tanto forças conservadoras e reativas quanto as ativas e transformadoras. No campo da política, falamos tanto da resistência negativa, que tende a reprimir fluxos emergentes, quanto das forças transformadoras que resistem à dominação, à sujeição, à exploração (Lhuilier \& Roche, 2009). A notar ainda que, em alguns desses movimentos, podem ocorrer contradições ou divisões internas. Não é sem razão que Lévy (2001) afirma que a mudança é um obscuro objeto do desejo. Para Foucault (1988), o tema da resistência se liga essencialmente à questão do poder. Ele também afirma que o conceito não é unívoco: onde há poder, há resistências, no plural, pois seus pontos são múltiplos, dinâmicos. De todo modo, só pode haver resistência no campo estratégico das relações de poder.

Outra observação essencial a respeito desta disciplina: ao ocupar-se, primordialmente, de fenômenos microssociais, sabendo que estes são atravessados pelas estruturas sociais globais, suas investidas teóricas também alcançam temas políticos e sociológicos na esfera macrossocial. A título de exemplo, cito a obra organizada por Pagès (2003), La violence politique, em que o autor aborda, no plano societário, o "inexplicável” da violência das guerras, dos massacres, dos genocídios, do terror revolucionário e contrarrevolucionário de outrora e de hoje. O livro também interroga os elementos que fazem um conflito escapar das racionalidades que o justificavam na origem, transformandoas em paranoia coletiva, em uma lógica persecutória que inventa os inimigos a destruir. Daí a circularidade entre racionalidade, afetividade, fanatismo político e religioso (Enriquez, 2001), violência revolucionária, desencadeamento em atrocidades e extermínios coletivos. Em outro texto, ao discutir o tema do poder, Barus-Michel e Enriquez (2002) evocam situações que revelam sua figura mortífera: "campos de concentração, genocídio e etnocídio, povos submetidos à escravatura, indivíduos tratados como animais ... aos quais é retirada a possibilidade de se encarregarem do seu destino ..." (Barus-Michel \& Enriquez, 2002, p. 220).

No que se refere às relações de trabalho, afirmam que as "sociedades doentes" estão marcadas pelas técnicas de controle da divisão do trabalho e das tarefas. Nesse contexto, o signo da perversão é a transformação das relações humanas em relações de objeto, nas quais os sujeitos devem, definitivamente, desaparecer. A abolição da escravatura não se baseou apenas nas ideias reformistas ou desinteressadas, mas, sobretudo, na suposta liberdade de empreender, concomitantemente ao desenvolvimento do capitalismo predador de vidas humanas e do planeta.

Além dos autores acima, citemos também Gaulejac (2007), que apresenta uma crítica radical ao poder gerencialista atrelado à ideologia neoliberal que, ao fomentar o culto, ou melhor, “o custo da excelência" (Aubert \& Gaulejac, 1991) e do alto desempenho, em uma obsessão pela rentabilidade financeira ou pela quantofrenia, semeia uma competição brutal no mercado em um ambiente de guerra econômica. Esta atinge os trabalhadores sob pressão e assédio, vítimas de doenças profissionais e acidentes de trabalho, além das novas patologias laborais, como depressão, burnout, uso de drogas, toda sorte de desgaste e sofrimentos físicos e psíquicos.

Essas questões da violência nas relações de trabalho e no plano macrossocial serão retomadas mais adiante neste texto, quando discutiremos os temas do precariado e da necropolítica.

Passemos agora à derivação recente da psicossociologia, ou seja, a "psicossociologia do trabalho". Esta, segundo Lhuilier (2014, p. 5): 
... não pode ser uma psicossociologia aplicada à cena do trabalho, entendido somente como um segmento da vida social. Ela implica uma reavaliação do quadro teórico e metodológico da psicossociologia sob o prisma dos conceitos de atividade, de ação e de práxis. Para isso, no entanto, ela não se propõe a romper com os antecedentes da psicossociologia, mas sim a revisitá-los, a fim de desenvolvê-los.

Entendemos que a psicossociologia do trabalho, não rompendo com as bases da disciplinamãe, abre novos horizontes, construídos especialmente a partir do conceito da atividade, em uma conotação ampliada deste conceito em relação à proposta inicial da ergonomia.

Com efeito, para Lhuilier (2017), a atividade funda a construção do sujeito e das unidades sociais, ela é, simultaneamente, produção de si e do mundo, quando está em análise a unidade dialética das atividades humanas. Nesse caso, a autora questiona "a dicotomia entre o fazer e o agir, a poiesis e a práxis; de outro lado, a clivagem entre trabalho e não trabalho, vida profissional e extra-profissional" (Lhuilier, 2017, p. 300). Isso significa que todo indivíduo está imerso na situação de trabalho com toda a sua biografia, é o mesmo sujeito que transita dentro ou fora do ambiente de trabalho, na vida privada ou em outros espaços de sociabilidade.

Nessa mesma linha, vale assinalar que a atividade de trabalho é tomada também como sinônimo de ação. Aqui, a autora critica as análises que consideram o trabalho (no sentido de trabalho estranhado ou alienado) como a parte maldita da atividade humana, em oposição à sua parte nobre, o campo do político. Essa desvalorização do trabalho e das atividades produtivas é acompanhada de uma valorização da práxis e da ação. Ela se inscreve na reta linhagem das conceitualizações de Arendt (1958) e da distinção que ela propõe entre trabalho, obra e ação (Lhuilier, 2017).

A poiesis não designa apenas as atividades úteis, nelas se desvelam as habilidades, o saberfazer, a expertise do ofício. Mais do que isso, grande parte de nosso "fazer" contém nosso "agir". Afinal (e aqui deve-se assinalar a distinção seminal entre atividade e tarefa), não há atividades sem perspectiva de ação, sem debate de valores. "Sustentamos que a atividade tem sempre uma dimensão política, que as duas dimensões, poiesis e praxis, atravessam todas as atividades humanas" (Lhuilier, 2016, p. 135).

Assim, as atividades têm sempre uma face instrumental e outra política, elas são permeadas pelas questões dos fins e dos meios. Pesquisas ligadas à saúde no trabalho (Canguilhem, 1947; Dejours, 2012; Hamraoui, 2014; Le Guillant et al., 1956; Lhuilier, 2002; Oddone, Re \& Briante, 1977) mostram justamente que, quando a atividade é desvinculada da praxis, reduzida a gestos e condutas mecânicas, o sujeito se enfraquece e sua vida psíquica se deteriora.

Lhuilier (2014) assinala que o "fazer sociedade" ou trabalhar no sentido de construção do laço social é um processo que implica a transformação da realidade em um jogo dialético de conflito e cooperação entre os atores sociais. No entanto, a conflitualidade não se reduz às relações interpessoais, ao puro embate de poder entre sujeitos. Ela comporta um terceiro termo que é a realidade a ser transformada e se torna o mediador das relações entre sujeitos. A autora evoca as contribuições de Gérard Mendel (1998) e seus conceitos de ato-poder e apropriação do ato. O ato-poder comporta dois significados: "o poder do ato como capacidade de transformação da realidade; e o poder sobre o ato" (Mendel, 1998, p. 10), disponível ao sujeito. O movimento de apropriação remete ao desenvolvimento da atividade, que a torna mais consciente e voluntária. Isso se contrapõe ao fazer mecânico, à mera tarefa imposta ao trabalhador. A apropriação compreende, pois, uma atividade que o sujeito assume de acordo com seus valores. Além disso, o poder do sujeito sobre o ato não significa apenas uma escolha pessoal, mas um conjunto de "ações coletivas capazes de modificar as normas de trabalho. Ela resulta, portanto, de um trabalho individual e coletivo de renormalização" (Mendel, 1998, p. 10).

Outra questão destacada por Lhuilier (2016): a atividade solicita a economia psicossomática. O "parar de trabalhar", no desemprego ou no "ser jogado no armário" (na empresa, na prisão, 
em um leito por doença incapacitante, em uma aposentadoria sem atividade), pode paralisar a solicitação do corpo e do pensamento. A energia contrariada ou inibida gera uma tensão interior, uma repressão interna, podendo ter dois efeitos: "a passagem ao ato (no sentido de acting-out, de condutas impulsivas), e as afecções psicossomáticas, sob a forma de irrupção de novas patologias ou do agravamento de patologias crônicas até então estabilizadas" (Lhuilier, 2016, p. 139).

Outra observação já evocada acima: mesmo que a atividade seja tomada como singular, ela é sempre associada à atividade do outro, no quadro de uma história coletiva que se torna fonte de novos recursos e resiste a cair na repetição de assujeitamentos. Não trabalhamos jamais sozinhos. O trabalho se efetua com o outro ou sob o olhar do outro, presente ou imaginado. Nós nos movemos sempre no horizonte inelutável da alteridade, mesmo que esta apareça como dupla fonte de conflito e de reconhecimento.

Lhuilier $(2016,2017)$ ainda aborda o trabalho como instituição, resultado da construção da sociedade e da cultura. Ele não se reduz às atividades remuneradas no âmbito dos processos produtivos. Como instituição, situado no tempo e na história, o trabalho sustenta e legitima atividades sociais, como cuidar, educar, governar, amar, vigiar, produzir etc. Abordar o trabalho como instituição é também discutir suas finalidades, ou seja, ele não responde apenas à pergunta "como fazer", mas também ao "por que fazer". Essa distinção é crucial, pois aqui se coloca a questão da racionalidade instrumental, na qual os meios tendem a prevalecer sobre os fins.

\section{O fenômeno da precarização}

As considerações acima se referem ao trabalho, de um lado, como uma categoria antropológica que funda a construção do sujeito e o "fazer sociedade"; de outro, elas apontam para a racionalidade perversa que desemboca na destruição física e psíquica dos indivíduos, reificados e instrumentalizados para a produção, sufocados como classe social. Neste sentido, o cenário contemporâneo do trabalho nos escancara, sob novas configurações, a questão da precarização, bastante próxima da condição escrava do trabalhador.

Para abordar este tema, já largamente explorado entre pesquisadores da área, recorro ao conceito de precariado (Alves, 2013; Braga, 2012, 2017, 2018; Braga \& Marques, 2017; Standing, 2011). O termo é um amálgama de "proletário" e "precário", utilizado por Castel (1998) em sua discussão sobre a precarização salarial e, mais tarde, por Standing (2011), que vê o precariado como uma nova classe social composta por trabalhadores, em geral bem qualificados, mas vivendo em permanente insegurança laboral, com sofríveis condições de trabalho e sem uma identidade fundada nele. Em 2000, um movimento deflagrado por trabalhadores em Milão, com manifestações de rua, depois conhecido como MayDay ou parada dos precários, se espalhou por toda a Europa.

Referindo-se ao termo, Braga (2018) aponta uma parcela crescente de trabalhadores atrelados a relações de trabalho precarizadas, como os empregos de alta rotatividade e instabilidade. $\mathrm{O}$ autor não se refere apenas ao trabalhador de salário mínimo, às famílias de baixa renda que moram nas periferias das grandes cidades, mas a uma camada de universitários, pessoas diplomadas e qualificadas, ora desempregadas, ora trabalhando como pessoa jurídica (PJ), sem direitos trabalhistas, sem perspectiva de aposentadoria, com renda instável e insegura, além de jornadas de trabalho muito mais longas. Para esse sociólogo, o precariado evidencia a estagnação dos empregos formais e o aumento dos subempregos. Tal fenômeno, no Brasil, reflete, entre outros fatores, uma crescente concentração de renda, gerando o enorme aumento da desigualdade em diversos planos da existência individual e coletiva. Uma matéria da Folha de S.Paulo (Braga, 2018) sobre uma pesquisa do IBGE mostra que o rendimento médio mensal da faixa do $1 \%$ mais rico da população brasileira atingiu, em 2018, o equivalente a 33,8\% do ganho obtido pelos 50\% mais pobres. De 2017 para 2018, 
o ganho dos $10 \%$ mais pobres caiu em $3,2 \%$, enquanto o do $1 \%$ mais rico aumentou $8,4 \%$. O aumento da concentração da renda é também, evidentemente, gerador de violência social. Nesse cenário, mesmo com eventual aumento de empregos, a maioria informais, os trabalhadores não têm acesso aos direitos trabalhistas e sociais. As oportunidades de trabalho que aparecem são ultraflexíveis, no sentido de prejuízo ao trabalhador, dado o alinhamento ideológico e político dos nossos legisladores à política ultraliberal. Com o desmonte do Estado de bem-estar social, soltam-se as rédeas para o mercado e a economia se autogovernarem, degradando as relações de trabalho anteriores, gerando o crescimento da informalidade. O precariado se alastra no Brasil em uma escala sem precedentes.

Lembremos, de passagem, que, em 2017, o país teve a reforma trabalhista do governo Temer, costurada à luz da desregulamentação dos direitos trabalhistas, atendendo a interesses econômicos e acordos políticos entre legisladores e representantes do grande capital. E, ao contrário do que proclamou aquele governo à época, a reforma não resultou em redução consistente do desemprego nem da informalidade do trabalho.

Para Braga e Marques (2017), o precariado não se localiza nem nos estratos sociais que Marx chamou de lumpemproletariado (grupos socialmente inferiores ao proletariado, parcelas miseráveis da população, sem recursos econômicos e sem consciência política ou de classe), nem nos setores profissionais mais qualificados, mais bem remunerados e estáveis da classe trabalhadora. O precariado não é um subproduto da crise do fordismo, mas uma dimensão intrínseca ao processo de mercantilização do trabalho. Nele se configura "a dimensão histórica e relacional desse grupo como parte integrante da classe trabalhadora, e não como um amálgama intergeracional e policlassista que assumiria de maneira progressiva a aparência de uma nova classe" (Braga \& Marques, 2017, p. 59).

O conceito de precariado é também discutido por Alves (2013) com algumas nuances. Para esse autor, ele se aplica à camada média do proletariado urbano formada por jovens-adultos, em geral altamente escolarizados, mas tendo inserção precária tanto nas relações de trabalho quanto na vida social. Ele critica Standing (2012), que define o precariado como uma nova classe social ou com uma "classe perigosa". Para Alves (2013), a parcela estável de trabalhadores dos países capitalistas centrais sempre continuou como parte do proletariado, embora como uma camada social distinta. Ele afirma que, mesmo à época da idade de ouro do fordismo-keynesianismo, o proletariado incluía categorias sociais precarizadas, em uma "economia subterrânea". Existe uma unidade política do proletariado, sendo o precariado uma camada social dessa classe.

Alves (2013) também questiona Ruy Braga, que assimila o precariado apenas ao proletariado precarizado, pois se perderia "a particularidade heurística do conceito capaz de dar visibilidade categorial às novas contradições do capitalismo global". O precariado não seria uma classe social específica, mas um contingente constituído pelo proletariado urbano precarizado no novo mundo do trabalho: operários altamente escolarizados, nos setores de serviço e comércio, jovens-adultos recém-graduados, estudantes de nível superior estudando e trabalhando com baixos salários. Aí haveria a junção da precarização salarial com a precarização existencial - um proletariado jovem, escolarizado, cultivando o ethos de classe média em seus anseios de ascensão e consumo, sujeito a "um misto de frustração de expectativas e insatisfação social e, por outro lado, carecimentos radicais que o tornam susceptível de atitudes de rebeldia". Trata-se de uma juventude proletária escolarizada sujeita ao desalento, frente à impossibilidade da sociedade das mercadorias em lhe oferecer uma vida plena de sentido.

Vale lembrar, em curto retrospecto histórico relativo às perdas dos direitos trabalhistas e ao declínio da inserção social da classe trabalhadora, o cenário que Castel (1998) denominou sociedade salarial, consolidada em meados do século XX, sob o Estado de bem-estar social, que garantia aos trabalhadores os suportes sociais ou a propriedade social (Castel \& Haroche, 2001), como aposentadoria, seguro-desemprego, férias, assistência à saúde, todo o aparato que conhecemos como seguridade social. 
Isso ocorreu à época dos "trinta anos gloriosos" nas sociedades capitalistas avançadas, entre o pós-Segunda Guerra e meados da década de 1970. Nessas sociedades, mesmo a despeito de suas camadas sociais marginalizadas, a atividade assalariada torna-se a forma hegemônica de inserção ou pertencimento social. Mas tal cenário começa a degradar-se, em seguida, dando lugar a uma nova ordem econômica mundial, a partir do primeiro "choque do petróleo", em 1973.

A crise da sociedade salarial surge com o declínio da hegemonia taylor-fordista, com a reestruturação produtiva, fundada na flexibilização das relações de trabalho, no contexto de globalização da economia, levando à desestruturação dos arranjos sociais anteriores. As reformas que surgem visam diminuir os custos do trabalho, fragilizando a condição salarial, alastrando a precariedade do emprego, como contrato por tempo determinado, tempo parcial, trabalho temporário, subcontratos etc. É aí que Castel situa a nova questão social, com a fragilização das relações salariais, a desestabilização e o aumento da insegurança que geram as zonas de invalidação ou desfiliação social do trabalhador. $O$ trabalho perde seu poder de integrar socialmente e garantir as proteções sociais. Observe-se que, se essa "propriedade social" não chegou a se consolidar satisfatoriamente no Brasil, pelo menos os trabalhadores já tiveram seus direitos mais protegidos que no momento atual, em que a reforma trabalhista vem coroar o desmonte progressivo da legislação trabalhista, guiado pelo ideário ultraliberal.

A questão da precarização do trabalho tem sido notavelmente atualizada por Antunes $(2014,2018)$, por meio de suas análises da reestruturação do capitalismo global, que desemboca em uma nova morfologia do trabalho e da qual emerge, entre outros fenômenos, o proletariado submetido à hegemonia das tecnologias digitais, principalmente na área de serviços, onde a figura do "trabalhador uberizado" toma a frente da cena. Seus efeitos são a degradação das relações de trabalho, já precedida pela série de precarizações, como a terceirização, a desregulamentação das relações de trabalho, ancoradas no discurso enganoso do empreendedorismo, no assédio crescente, no adoecimento, na ausência de proteção sindical ou de formas de organização solidária entre eles.

Nesse contexto de desregulamentação, a reforma levada a termo no governo Temer, por meio da Lei no 13.467, de 2017, trouxe o maior conjunto de modificações na Consolidação das Leis do Trabalho (CLT), com expressiva perda dos direitos dos trabalhadores. Ajuntemos a ela a Emenda Constitucional 95, também apelidada de "PEC da morte", que instituiu um novo regime fiscal, limitando o crescimento das despesas públicas durante 20 anos, com impacto altamente deletério nas políticas de proteção a todos os cidadãos.

Esse desmonte dos direitos sociais e do trabalho tem sido aprofundado no governo Bolsonaro, tanto com a reforma da Previdência, em 2019, nociva não apenas aos trabalhadores que vão ingressar no mercado de trabalho, mas também àqueles já inseridos nele. Essa reforma vem acompanhada de diversas medidas (não importa se algumas são revogadas ou modificadas por serem inconstitucionais) que lhes retiram proteções, como a "carteira verde amarela", além das MPs que incluem acordos individuais para redução da jornada e do salário, sempre em benefício do empregador - ou do capital.

\section{A necropolítica}

Entre os temas caros à psicossociologia, citamos acima a questão da violência política (Pagès, 2003), encarnada em guerras, massacres, genocídios, racismo, terrorismo, entrelaçados a fenômenos como a paranoia coletiva, cuja lógica persecutória engendra os inimigos a destruir. No livro La face obscure des démocraties modernes, Enriquez e Haroche (2002) também discutem questões macrossociais, ao repensar as raízes da violência e da destrutividade nas sociedades ditas civilizadas, em um diálogo entre a sociologia, a política e a psicanálise. Nessa encruzilhada teórica, eles apontam uma "tendência espontânea" dos grupos humanos em adotar condutas destrutivas. 
Julgamos que essas discussões permitem uma articulação pertinente com o conceito de necropolítica, consagrado pelo cientista social moçambicano Achilles Mbembe (2016). Este autor critica o pensamento que privilegiou as teorias normativas da democracia que tomam a razão como um de seus pilares, ao afirmar que a modernidade fez nascerem diferentes conceitos de soberania. Em seu ensaio "Necropolítica", Mbembe (2016) comenta que a noção clássica de soberania se baseia no estabelecimento de normas gerais para homens e mulheres livres e iguais. A política comportaria um projeto de autonomia regida por acordos em uma coletividade, nos registros da comunicação e do reconhecimento. E aí estaria um paradigma político que se diferencia da guerra. Nele, "a razão é a verdade do sujeito, e a política é o exercício da razão na esfera pública" (Mbembe, 2016, p. 124). Razão e liberdade definiriam a autonomia individual. Tal soberania sustenta a crença de "um sujeito autor e controlador de seu próprio significado" e supõe um processo de autoinstituição e autolimitação, assim como a capacidade da sociedade de se autocriar, por meio das instituições, movida por "significações específicas sociais e imaginárias" (Mbembe, 2016, p. 124).

Essa leitura normativa, segundo o autor, não resiste a questionamentos. Ela se detém nas formas de soberania centradas não na luta pela autonomia, mas na "instrumentalização generalizada da existência humana e na destruição material de corpos humanos e populações" (Mbembe, 2016, p. 125). Acrescente-se que tal exercício de soberania, longe de ser mera insanidade, constituiria o nomos do espaço político em que vivemos. Em vez da razão, como verdade do sujeito, teríamos outras categorias fundadoras mais patentes, como a vida e a morte.

A partir de colocações de Hannah Arendt e Giorgio Agamben sobre os campos de concentração nazistas e do conceito de Estado de exceção, Mbembe (2016) identifica uma estrutura políticojurídica e subjetiva que reduz o indivíduo ao seu corpo biológico, retirando-lhe o estatuto político, o que abre espaços para o "trabalho de morte". O Estado de exceção que, nesse caso, se torna regra, seria "a base normativa do direito de matar" (Mbembe, 2016, p. 128) e o poder soberano seria esse direito de matar e deixar viver.

É dessa racionalidade de certas políticas contemporâneas que emerge a noção ficcional de sujeitos "inimigos" da ordem e da razão. A lógica desse modelo define quem importa ou não, quem é descartável ou não, quem deve viver e quem deve morrer. Nesse caso, a soberania se define como o direito de matar ${ }^{2}$. Mbembe (2016) relata que sua abordagem se baseia na crítica de Michel Foucault $(1988,1997)$ ao conceito de soberania e à sua relação com a guerra e o biopoder. Aqui, se encontram as noções de necropoder e biopoder. Elas operam em relação a um campo biológico, distribuindo a espécie humana em grupos e subgrupos, praticando uma cesura biológica entre eles. É isso que Foucault chama de racismo. Para ele, a raça sempre teria sido a sombra presente no pensamento e na prática das políticas do Ocidente.

Mbembe (2016) ainda observa que Hannah Arendt localiza as raízes do racismo na experiência demolidora da alteridade, daí a política da raça estar ligada à política da morte. Em termos foucaultianos, o racismo é uma tecnologia a serviço do biopoder e sua função é regular a distribuição da morte e tornar possível as funções assassinas do Estado. O Estado nazista, para Foucault, seria "o mais completo exemplo de um Estado exercendo o direito de matar" (Mbembe, 2016, p. 128), que culminou no projeto da "solução final". Lembremos que, para Mbembe, as formas de conduzir pessoas à morte ou a eliminação dos "inimigos do Estado" remontam aos tempos do imperialismo colonial, ao período da escravidão.

Ao discutir os temas do biopoder e da necropolítica, Hilário (2016) afirma que Foucault considerou o biopoder como elemento indispensável ao desenvolvimento do capitalismo,

2 Lembremos, de passagem e como contraponto a esse direito de matar, a forte reação americana e mundial ao racismo, com o lema black lives matter, após o bárbaro assassinato do negro George Floyd por um policial branco. 
no sentido da inserção controlada dos corpos no aparelho de produção. O poder produz subjetividades adequadas às formas sociais, segundo a dinâmica do capitalismo em ascensão que, para se manter, necessita das vidas, dos corpos, como máquinas produtivas, força de trabalho para a produção de mercadorias. O corpo é a realidade política por excelência, por meio da qual o poder se atualiza e se legitima.

No entanto, o que ocorreria se a vida não fosse mais um elemento indispensável? Ou quando o modo de produção capitalista passar a precisar cada vez menos de força de trabalho? A estratégia do capital será "jogar pessoas no desemprego estrutural, empurrá-las para as periferias da cidade, para as prisões ou simplesmente aniquilá-las por meio das forças policiais, oficiais ou não" (Hilário, 2016, p. 202). Este autor lembra que, em algumas cidades do México, ocorreram processos violentos de assassinatos, desaparições, execuções sumárias extrajudiciais, exemplos de um "trabalho de morte" perpetrado por máquinas de guerra privadas, como milícias, mercenários, segurança privada etc. Ao mesmo tempo, ele se pergunta sobre o que se passa no Brasil, onde o "trabalho de morte" vem acontecendo desde muito tempo. E cita o caso da polícia militar do Rio de Janeiro, que cometeu mais de 10 mil homicídios entre 2001 e 2011, grande parte das vítimas menores de 18 anos.

Ainda para caracterizar o conceito de necropoder ou necropolítica, Zaccone (2015, citado por Hilário, 2016, p. 207) afirma que "a polícia mata, mas não mata sozinha”, ou seja, "existe uma política pública, na forma de razões de Estado, a ensejar os altos índices de letalidade do sistema penal brasileiro, com destaque para aqueles praticados rotineiramente nas favelas cariocas". A este respeito, o jornal El País (Betim, 2019) lembra que o governador do Rio de Janeiro, Wilson Witzel, desde sua campanha eleitoral, já liberava aos policiais a licença para matar. De fato, as polícias civil e militar, sob o seu comando, desde janeiro de 2019, já eram responsáveis por 41,5\% das mortes violentas na região metropolitana do Rio de Janeiro, 178 mortes cometidas por agentes, segundo informação do Instituto de Segurança Pública (ISP), autarquia ligada ao governo. Só no mês de julho de 2020, a polícia matou entre seis e sete pessoas por dia 3 .

Vemos que, em tempos de sujeitos não necessários para a produção, o homem que sobra é uma vida sem valor, o homo sacer, matável (Agamben, 2010). A necropolítica visa à destruição material dos corpos, das massas humanas consideradas descartáveis, supérfluas. Vale notar que, no Brasil, a necropolítica não é privilégio do estado do Rio de Janeiro. Além disso, assistimos a tentativas quase contínuas de implantação de necropolíticas pelo próprio Estado brasileiro. Entre os muitos exemplos, citemos o projeto de lei ou "pacote anticrime" elaborado pelo ex-ministro da Justiça, Sérgio Moro, com a sua cláusula do "excludente de ilicitude", que concederia legalmente aos policiais a licença para matar. E o que dizer da omissão planejada do presidente Bolsonaro, ao responder "E daí? Quer que eu faça o quê?" à jornalista que, em 28 de abril de 2020, o questionou sobre o fato de o Brasil ter ultrapassado a China, em número de mortes pela Covid-19.

Ainda em relação à necropolítica e à Covid-19, citemos a situação de dois extratos da população brasileira que, se já secularmente discriminados, estão agora mais desamparados pelas condutas do atual governo: os povos indígenas e os quilombolas. Cardoso (2020), pesquisador da Fiocruz e estudioso das populações indígenas, já previa, no começo da pandemia no Brasil, que, se o Coronavírus atingisse essas comunidades, sua incidência seria explosiva, já que elas são extremamente vulneráveis à pandemia, em razão de suas condições sociais e econômicas precárias, da falta de saneamento básico, do modelo de habitação coletiva em grandes moradias, entre outras razões. Para o pesquisador, a saúde dos índios é, em geral, mais frágil que a dos não índios, e suas infecções respiratórias se propagam rapidamente. Quanto maior for sua proximidade com centros urbanos, maior o risco de transmissão comunitária da doença. Ora, os territórios indígenas são cada vez

3 O site UOL, em 7 de maio de 2019, publicou que a Comissão de Direitos Humanos da Assembleia Legislativa do Rio de Janeiro e a deputada federal Talíria Petrone (PSOL-RJ) denunciaram à ONU a "agenda genocida" de Witzel. (Saboia, 2019). Eles afirmam ainda que as mortes por policiais no estado do Rio atingiram um nível recorde no primeiro trimestre de 2019. 
mais invadidos, no atual governo, por grileiros, madeireiros ilegais e garimpeiros. Haveria, por exemplo, cerca de 20 mil garimpeiros na terra indígena Yanomami (AM-RR), contra uma população aproximada de 26,7 mil indígenas. Ajuntemos a isso a onda de assassinatos de líderes desses povos, no território brasileiro, sob o silêncio de atual presidente. Em janeiro de 2020, 45 etnias se reuniram na terra indígena Capoto Jarina, no Mato Grosso, convocadas pelo cacique Kayapó Raoni Metuktire. Nessa reunião, foi lançado um manifesto afirmando que "está em curso um projeto político do governo brasileiro de genocídio, etnocídio e ecocídio” (Fellet, 2020). A situação se agravou a tal ponto que, em 3 de julho de 2020, o Tribunal Regional Federal da 1를 Região (TRF1) acatou o pedido do Ministério Público Federal (MPF), propondo um plano emergencial do governo para conter o avanço da Covid-19 nas terras indígenas de Roraima. Esse plano incluía a retirada dos garimpeiros ilegais das terras dos Yanomami.

Outro núcleo populacional ameaçado, no Brasil, pela necropolítica vigente no atual governo são as comunidades quilombolas. Cito, a esse respeito, uma matéria publicada pelo Sindicato Nacional dos Docentes das Instituições de Ensino Superior (Andes) (“Governo quer expulsar”, 2020), que denuncia o projeto do governo de expulsar 800 famílias de 30 comunidades quilombolas das terras em que habitam, há mais de três séculos, no município de Alcântara, MA. Esse projeto está oficializado na Resolução n⿳ำ 11/2020, de 26 de março de 2020, que prevê a utilização da área ocupada por essas comunidades na expansão do Centro de Lançamento de Alcântara (CLA) (Brasil, 2020). Essa resolução foi editada já na eclosão da atual pandemia. Segundo o texto da Andes ("Governo quer expulsar", 2020), o projeto de desocupação do território pelos quilombolas desconsidera a "Convenção 169 da OIT sobre povos indígenas e tribais", de 7 de junho de 1989, que prevê uma consulta prévia, livre e informada aos seus principais interessados. Em síntese, em meio a uma pandemia de proporções até agora incontroladas, essas comunidades ficam à mercê de um governo que lhes retira as terras, o sustento e os direitos fundamentais.

\section{E a saúde do trabalhador?}

No atual cenário de perdas de direitos humanos e dos direitos trabalhistas, permito-me abordar o drama específico dos milhares de homens e mulheres adoecidos no e pelo trabalho, em um contexto de insegurança, desamparo, assédio e outros constrangimentos, que resultam em crescente incidência do adoecimento mental. Observe-se que, em princípio, todos os trabalhadores brasileiros, formais ou informais, ativos ou inativos, estão protegidos pelo texto Constitucional de 1988, que atribui ao Sistema Único de Saúde (SUS) a garantia da atenção integral à saúde dos cidadãos. Nele, está incluído o universo multifacetado de trabalhadores, conforme define o artigo terceiro da Portaria no 1.823 , de 23 de agosto de 2012:

Todos os homens e mulheres, independentemente de sua localização, urbana ou rural, de sua forma de inserção no mercado de trabalho, formal ou informal, de seu vínculo empregatício, público ou privado, assalariado, autônomo, avulso, temporário, cooperativados, aprendiz, estagiário, doméstico, aposentado ou desempregado (Ministério da Saúde, 2012).

Vemos aqui o arcabouço legal para a segurança, a proteção e a promoção da saúde de todos os trabalhadores. Cabe ao SUS a implementação das ações de assistência e vigilância em saúde, controlando e prevenindo as doenças relacionadas ao trabalho. Ressalte-se ainda que, em termos de política pública, os avanços nos governos anteriores fortaleceram a rede de atenção à saúde do trabalhador, como a criação, em 2002, da Rede Nacional de Atenção à Saúde do Trabalhador (Renast) (Ministério da Saúde, 2006), organizada a partir dos Centros de 
Referência em Saúde do Trabalhador (Cerests). Esses avanços foram ainda mais revigorados com a criação, em 2012, da Política Nacional de Saúde do Trabalhador e da Trabalhadora (PNSTT) (Ministério da Saúde, 2012). No entanto, no atual cenário de precarização e desmonte das relações de trabalho, perguntamo-nos se o próprio SUS tem condições institucionais e logísticas (lembremos a PEC 95) para assegurar a atenção integral aos trabalhadores. Note-se que o atual governo tem buscado, gradativamente, o desmantelamento do SUS, como, por exemplo, a proposta do fim da gratuidade universal, prevista no Programa Previne Brasil (Ministério da Saúde, 2019), que altera a distribuição das verbas de financiamento da atenção básica, visando manter como usuários do sistema apenas as pessoas cadastradas nos municípios. Isso equivale ao fim do "SUS para todos” e aponta mais um retrocesso nas políticas de atenção integral à saúde dos cidadãos.

No caso do trabalhador - e este é o ponto que pretendo realçar - um dos aspectos fundamentais da atenção integral é a vigilância e a prevenção dos agravos da saúde na dimensão da saúde coletiva. Note-se que cuidar apenas do sujeito já acidentado ou adoecido é excluir a vigilância, é amputar a própria política do SUS. No atual cenário de precarizações, se levarmos em conta, por exemplo, somente os trabalhadores por aplicativos, temos de perguntar: como fazer a vigilância e a prevenção desse coletivo, fora dos tradicionais espaços fixos de trabalho (fábricas, lojas de departamento, restaurantes industriais...)? Onde e como os agentes da saúde vão localizar esses espaços, atualmente dispersos, móveis ou mesmo imateriais, como os ambientes virtuais? Onde e como encontrar o motoboy, o motorista de Uber, o bikeboy, o ambulante, o gerente em "home-office" (que pode estar em qualquer lugar, se o seu "escritório" é o laptop)? Certamente essa tarefa pode ser realizada com facilidade, do ponto de vista puramente técnico, por recursos digitais de buscas. Mas, antes disso, temos de perguntar se a asfixia dos projetos de saúde (em um governo que fica sem ministro da saúde por meses em plena pandemia) permite a seus gestores e profissionais traçar estratégias para levar aos trabalhadores as informações necessárias à prevenção e ao cuidado de si e da sua categoria, além de discutir com eles os problemas sanitários, ergonômicos, jurídicos, ecológicos e outros, relativos à sua inserção no mercado de trabalho.

\section{Resistência e limites das organizações alternativas}

As discussões acima mostram que é cada vez mais desafiador pensar estratégias de resistência e enfrentamento da vulnerabilidade dos trabalhadores, após as recentes reformas trabalhista e previdenciária, no Brasil. Entre as ações que poderiam contrapor-se a esse trágico quadro social, podemos citar a produção e a divulgação do conhecimento relativo à miserabilidade da desfiliação social de milhões de brasileiros, seja no espaço acadêmico, no campo das artes e das tecnologias de informação e comunicação. Isso envolveria pesquisadores, artistas, jornalistas, sindicatos, movimentos sociais e trabalhadores não organizados formalmente. Uma segunda forma de resistência estaria nas experiências de trabalho que se contrapõem ao sistema capitalista, a exemplo da economia solidária e tantos outros projetos de cunho comunitário ou cooperativo. Gaulejac (2007) considera que o gerencialismo neoliberal, em uma sociedade "doente da gestão", isola o sujeito, em vez de o agrupar, pois só entende a existência de equipes feitas para produzir cada vez mais, em um ritmo mais acelerado e a baixo custo. Para tal ideologia, diz o autor, a solidariedade no trabalho é antiprodutiva. Contrariamente a essa tese, ele afirma que "a economia solidária é um projeto equivalente à não-violência na política ... trata-se de romper com a ideia segundo a qual apenas a economia de mercado é produtora de riquezas" (Gaulejac, 2007, p. 305).

São inúmeras as experiências de trabalho cooperativo no Brasil e no mundo (Singer, 2008). Pelo fato de nos referirmos, neste artigo, aos trabalhadores precarizados de aplicativos, citemos algumas iniciativas de resistência especificamente nesse campo. Lembremos, primeiro, o que 
ocorreu, no dia $1^{\circ}$ de julho de 2020: uma greve dos entregadores de aplicativos (iFood, Rappi, Uber Eats etc.) que teve a adesão de milhares de trabalhadores em várias capitais do país. A greve foi o início de uma luta direta no Brasil contra o chamado ubercapitalismo, visando a mudanças nas relações excessivamente abusivas de trabalho. Note-se que a greve é uma forma clássica de luta operária. Já as experiências solidárias buscam enfrentar o capitalismo por meio de alternativas, como é o caso do "cooperativismo de plataforma" (Sholz, 2016), que se contrapõe aos arranjos do "capitalismo de plataforma", que não visa ao bem comum, e seu caráter inovador só veio a aumentar a vulnerabilidade do trabalhador já precarizado.

No entanto, mesmo esse "cooperativismo de plataforma" é objeto de questionamentos. Grohmann (2018), por exemplo, interroga o alcance de sua potência para contestar o capitalismo. Ele se refere aos riscos de a cooperativa ser idealizada em seu poder emancipatório e de transformação social ou de ter seu projeto despolitizado, quando adere ao modelo-empresa. Este autor observa, no entanto, que a ambiguidade dos discursos relativos ao trabalho cooperativo, nas áreas da cultura e da comunicação, pode tanto estar próxima de um projeto cooperativo-empreendedor, nos moldes de uma startup, quanto lembrar, efetivamente, um projeto político de transformação social. Ao questionar as diferenças entre "cooperativismo de plataforma" e "capitalismo de plataforma", ele aponta, a um só tempo, "o potencial emancipatório e a natureza contraditória das cooperativas" (Grohmann, 2018, p. 23).

Voltemos ao tema da resistência, lembrando que o momento de pandemia da Covid-19 fez ressurgir inúmeras formas de solidariedade e de trabalho em diversos níveis de interação entre pessoas e grupos sociais. Note-se que o conceito de trabalho não se restringe às atividades produtoras de mercadorias no sistema capitalista de trocas. Em outras palavras, todos os participantes das ações de solidariedade, nos campos da cultura, da arte, dos movimentos sociais e políticos, são trabalhadores. Trabalhadores criativos e solidários, em diversas frentes de resistência a ações de necropolítica, no atual governo brasileiro. Hoje, inúmeros debates acadêmicos, assim como eventos artísticos, divulgados nas redes sociais (lives), configuram fenômenos de resistência, denunciando a violência estrutural, disseminada em todo o planeta, não só no Brasil. A arte mobiliza o pensamento e os afetos, fazendo do sonho, da utopia e da consciência do presente um instrumento coletivo de ação política.

\section{Considerações finais}

Ao iniciarmos este texto, apresentando alguns fundamentos da psicossociologia, quisemos nos servir deles para abrir caminho a discussões ligadas à precarização no trabalho, associando-as à questão mais ampla da violência no campo macrossocial. Para tanto, julgamos que a análise desses temas poderia se enriquecer, em um diálogo com autores cujas elaborações teóricas tivessem afinidades com a postura crítica da psicossociologia, no terreno do debate político contemporâneo. Quanto ao tema do trabalho, levantamos questões em torno da vulnerabilidade crescente das classes trabalhadoras, no contexto da ideologia neoliberal marcada por um poder gerencialista que faz da gestão uma "doença social", sob o signo de uma racionalidade perversa, que destrói física e psiquicamente os indivíduos sufocados como sujeitos, instrumentalizados para a produção, tendo seus direitos trabalhistas corroídos, levados ao adoecimento e à morte (Enriquez \& Haroche, 2002; Gaulejac, 2007; Lhuilier, 2016). Visamos rediscutir essas questões, aproximando-as do conceito de precariado, com base nas teorizações de Braga (2012) e Alves (2013), cujas contribuições ampliaram e enriqueceram a inteligibilidade da matéria, especialmente ao incluir novos atores sociais - universitários, jovens adultos diplomados e altamente qualificados - no perfil dos "precariados". 
Da mesma forma, julgamos pertinente estender a discussão sobre a violência, partindo do aviltamento das classes trabalhadoras, à dimensão macrossocial, que também é objeto das incursões teóricas da psicossociologia. A opção por aprofundar e atualizar o debate sobre "a face obscura das democracias modernas" e dos regimes autoritários, do fanatismo político e religioso, do terrorismo, da paranoia coletiva, assim como das várias faces da barbárie (Barus-Michel \& Enriquez, 2002; Enriquez \& Haroche, 2002; Pagès, 2003), foi recorrer às contundentes contribuições de Mbembe (2016) em torno do conceito de necropolítica. Este teórico político desnuda a racionalidade das soberanias que dizem tomar a razão como a verdade do sujeito e fundamento do exercício da política. Em vez disso, os Estados de exceção, afirma ele, assumem como base normativa o direito de matar e deixar viver, fazendo da política da raça a estratégia demolidora da alteridade, uma política da morte.

Ao recorrer aos autores acima, valendo-nos dos conceitos de precariado e de necropolítica, julgamos ter podido enriquecer as contribuições da psicossociologia em suas análises das condições de vulnerabilidade do trabalhador, bem como da instabilidade e da violência dos sistemas políticos contemporâneos. Pudemos, assim, assinalar alguns efeitos desses cenários no atual momento da realidade brasileira ao discutir, entre outras, a fragilidade da assistência pública à saúde dos trabalhadores ou a desproteção específica dos trabalhadores por aplicativos.

Concluindo, retorno à hipótese acima, relativa ao poder da arte como instrumento coletivo de mobilização política. Para ilustrá-la, evoco um dos mais importantes "escritores-militantes", artista da palavra e prêmio Nobel de literatura: José Saramago, que nos deixou em 2010. No fragmento de uma reflexão, ele alude ao que estamos chamando de "poder de morte", sob o império do neoliberalismo:

La alternativa al neoliberalismo se llama consciência. Lo que se está preparando en el planeta es un mundo para los ricos. Habrá pobres, pero el mundo será para el disfrute de los ricos. Entre 1.000 millones y 1.500 millones de seres humanos son para desechar ... Que más da que se maten unos cuantos miles, o muchisimos miles. Mientras se maten unos a los otros, no tendré yo que matarlos a ellos ... ¿Qué es lo que tenemos entonces para oponermos? Nada más que la conciencia ... La conciencia de que lo que está en el mundo me pertenece, no en el sentido de propriedad, me pertenece como responsabilidad, me pertenece como derecho a saber, como derecho a intervenir, como derecho a cambiar (Saramago, 1999).

\section{Referências}

Agamben, G. (2010). Homo Sacer: o poder soberano e a vida nua I (2 ${ }^{\underline{a}}$ ed.). Belo Horizonte: Editora UFMG.

Alves, G. (2013, 22 de julho). O que é o precariado? Blog da Boitempo. Recuperado de https://blogdaboitempo.com. br/2013/07/22/o-que-e-o-precariado/

Amado, G. (2002). Implication. In J. Barus-Michel, E. Enriquez \& A. Lévy (Orgs.), Vocabulaire de psychosociologie : références et positions (pp. 367-374). Toulouse : Érès.

Amado, G. \& Enriquez, E. (2011). Psicodinâmica do trabalho e psicossociologia. In P. F. Bendassolli \& L. A. P. Soboll (Orgs.), Clínicas do trabalho: novas perspectivas para a compreensão do trabalho na atualidade (pp. 99-109). São Paulo: Atlas.

Antunes, R. (2014). Desenhando a nova morfologia do trabalho no Brasil. Estudos Avançados, 28(81), 39-53.

Antunes, R. (2018). O privilégio da servidão: o novo proletariado de serviços na era digital. São Paulo: Boitempo.

Arendt, H. (1958). Condition de l'homme moderne. Paris : Calmann-Lévy.

Aubert, N. \& Gaulejac, V. (1991). Le coût de l'excellence. Paris : Seuil.

Barus-Michel, J. \& Enriquez, E. (2002). Pouvoir. In J. Barus-Michel, E. Enriquez \& A. Lévy (Orgs.), Vocabulaire de psychosociologie : références et positions (pp. 213-221). Toulouse : Érès.

Barus-Michel, J., Enriquez, E. \& Lévy, A. (Orgs.). (2002). Vocabulaire de psychosociologie : références et positions. Toulouse : Érès. 
Ben Slama, F. (1999). La question du contre-transfert dans la recherche. In C. R. d'Allonnes (Org.), La démarche clinique en sciences humaines (pp. 139-153). Malakoff: Dunod.

Betim, F. (2019, 21 de agosto). Sob Witzel, policiais já respondem por quase metade de mortes violentas na região metropolitana do Rio. El País. Recuperado de https://brasil.elpais.com/brasil/2019/08/21/politica/ 1566423448_948955.html

Braga, R. (2012). A política do precariado: do populismo à hegemonia lulista. São Paulo: Boitempo.

Braga, R. (2017). Rebeldia do precariado: trabalho e neoliberalismo no Sul global. São Paulo: Boitempo.

Braga, R. (2018). "Precariado" tende a se alastrar no Brasil como nunca antes (F. Ferreira, Entrevistadora). Recuperado de https://www1. folha.uol.com.br/mercado/2018/01/1951942-precariado-tende-a-se-alastrar-no-brasil-como-nunca-antes-diz-sociologo.shtml

Braga, R. \& Marques, J. (2017). Trabalho, globalização e contramovimentos: dinâmicas da ação coletiva do precariado artístico no Brasil e em Portugal. Sociologias, 19(45), 52-80.

Brasil. (2020). Resolução n⿳⼈ㅡㄹ 11, de 26 de março de 2020. Publica as deliberações do Comitê de Desenvolvimento do Programa Espacial Brasileiro na Sétima Reunião Plenária. Presidência da República. Recuperado de https:// www.in.gov.br/en/web/dou/-/resolucao-n-11-de-26-de-marco-de-2020-249996300

Canguilhem, G. (1947). Milieu et normes de l'homme au travail. Cahiers Internationaux de Sociologie, 3, 120-136.

Cardoso, A. M. (2020). Se o coronavírus entrar nas aldeias, é possível que o aumento de casos seja explosivo (O. B. Souza, Entrevistador). Recuperado de https://www.socioambiental.org/pt-br/noticias-socioambientais/se-coronavirusentrar-nas-aldeias-e-possivel-que-aumento-de-casos-seja-explosivo-alerta-especialista

Castel, R. (1998). As metamorfoses da questão social: uma crônica do salário. Petrópolis, RJ: Vozes.

Castel, R \& Haroche, C. (2001). Propriété privée, propriété sociale, propriété de soi. Paris : Fayard.

Clot, Y. (2010). Trabalho e poder de agir. Belo Horizonte: Fabrefactum.

Clot, Y. (2015). De Mayo à Oddone, l'instruction au sosie. In I. Oddone, A. Re \& G. Briante (Orgs.), Redécouvrir l'expérience du travail (pp. 7-34). Paris : Les Éditions Sociales.

Daniellou, F. (2015). L'ergologie, en dialogue parmi les ergo-disciplines. In L. Durrive (Org.), Léxpérience des normes, comprendre l'activité humaine avec la démarche ergologique (pp. 1-14). Toulouse : Octarès.

Dejours, C. (2012). Trabalho vivo. Brasília: Paralelo 15.

Deveureux, G. (1980). De l'angoisse à la méthode dans les sciences du comportement. Paris : Flammarion.

Enriquez, E. (2001). Fanatismo religioso e político. In M. M. Machado, E. M. Castro, J. N. G. Araújo \& S. Roedel (Orgs.), Psicossociologia: análise social e intervenção. Belo Horizonte: Autêntica.

Enriquez, E. \& Haroche, C. (2002). La face obscure des démocraties modernes. Toulose : Érès.

Fellet, J. (2020, 29 de janeiro). Os 5 principais pontos de conflito entre governo Bolsonaro e indígenas. BBC News Brasil. Recuperado de https:/www.bbc.com/portuguese/brasil-51229884/

Foucault, M. (1988). História da sexualidade I: a vontade de saber (13를 ed). Rio de Janeiro: Graal.

Foucault, M. (1997). Il faut défendre la société : cours au Collège de France (1975-1976). Paris : Seuil.

Gaulejac, V. (2001). Psicossociologia e sociologia clínica. In J. N. G. Araújo \& T. C. Carreteiro (Orgs.), Cenários sociais e abordagem clínica (pp. 35-47). São Paulo: Escuta.

Gaulejac, V. (2007). Gestão como doença social: ideologia, poder gerencialista e fragmentação social. Aparecida, SP: Ideias e Letras. Giust-Desprairies, F. (2001). O acesso à subjetividade: uma necessidade social. In J. N. G. Araújo \& T. C. Carreteiro (Orgs.), Cenários sociais e abordagem clínica (pp. 231-244). São Paulo: Escuta.

Governo quer expulsar quilombolas de suas terras em meio à pandemia de Covid-19. (2020, 2 de abril). Andes. Recuperado de https://www.andes.org.br/conteudos/noticia/governo-quer-expulsar-quilombolas-de-suas-terrasem-meio-a-pandemia-de-covid-191

Grohmann, R. (2018). Cooperativismo de plataforma e suas contradições: análise de iniciativas da área de comunicação no Platform.Coop. Liinc em Revista, 14(2), 19-32.

Hamraoui, E. (2014). Trabalho vivo, subjetividade e cooperação: aspectos filosóficos e institucionais. Cadernos de Psicologia Social e do Trabalho, 17 (spe1), 43-54.

Hilário, L. C. (2016). Da biopolítica à necropolítica: variações foucaultianas na periferia do capitalismo. Sapere Aude, $7(13), 194-210$. 
Le Guillant, L., Roelens, R., Bégoin, J., Béquart, P., Hamsen, M. \& Lebreton, F. (1956). La névrose des téléphonistes. La Presse Médicale, 64(13), 274-277.

Lévy, A. (2001). A mudança: esse obscuro objeto do desejo. In J. N. G. Araújo \& T. C. Carreteiro (Orgs.), Cenários sociais e abordagem clínica (pp. 121-131). São Paulo: Escuta.

Lewin, K. (1997). Resolving social conflicts and field theory in social science. Washington, DC: American Psychological Association. Lhuilier, D. \& Roche, P. (2009). Introduction. Nouvelle Revue de Psychosociologie, 7(1), 7-18.

Lhuilier, D. (2014). Introdução à psicossociologia do trabalho. Cadernos de Psicologia Social do Trabalho, 17 (spe.), 5-19.

Lhuilier, D. (2016). Lactivité dans et au-delà du monde du travail. In M. A. Dujarier, C. Gaudart, A. Gillet \& P. Lénel (Orgs.), L'activité en theories : regards croisés sur le travail (pp. 131-158). Toulouse : Octarès.

Lhuilier, D. (2017). O agir em psicossociologia do trabalho. Psicologia em Revista, 23(1), 295-311.

Lhuilier, D. (2002). Placardisés : des exclus dans l'entreprise. Paris : Seuil.

Martins, S. R. \& Mendes, A. M. (2012). Espaço coletivo de discussão: a clínica psicodinâmica do trabalho como ação de resistência. Revista Psicologia Organizações e Trabalho, 12 (2), 171-184.

Mbembe, A. (2016). Necropolítica. Arte Ë Ensaios, 32, 123-151.

Mendel, G. (1998). Lacte est une aventure : du sujet métaphysique au sujet de l'actepouvoir. Paris : La Découverte.

Ministério da saúde (2006). Rede Nacional de Atenção Integral à Saúde do Trabalhador: manual de Gestão e Gerenciamento. São Paulo: Hemeroteca Sindical Brasileira.

Ministério da Saúde. (2012). Portaria no 1.823, de 23 de agosto de 2012. Institui a Política Nacional de Saúde do Trabalhador e da Trabalhadora. Recuperado de http://bvsms.saude.gov.br/bvs/saudelegis/gm/2012/prt1823_23_08_2012.html

Ministério da saúde. (2019). Portaria n 2.979, de 12 de novembro de 2019. Institui o Programa Previne Brasil que estabelece novo modelo de custeio da atenção primaria à saúde no âmbito do Sistema Único de Saúde, por meio da alteração da Portaria de Consolidação no 6/GM/MS de 25 de setembro de 2017. Recuperado de https:// www.in.gov.br/en/web/dou/-/portaria-n-2.979-de-12-de-novembro-de-2019-227652180

Oddone, I., Re, A. \& Briante, G. (1977). Esperienza operaia, coscienza di classe e psicologia del lavoro. Turim: Einaudi.

Oddone, I. (2015). Redécouvrir l'expérience du travail. Paris : Les Éditions Sociales. (Original publicado em 1977).

Pagès, M., Bonetti, M., Gaulejac, V. \& Descendre, D. (1987). O poder das organizações. São Paulo: Atlas.

Pagès, M. (Org.). (2003). La violence politique. Toulouse : Érès.

Sabóia, G. (2019, 7 de maio). Witzel é denunciado à ONU por recorde de mortes em ações policiais no Rio. UOL. Recuperado de https:/noticias.uol.com.br/cotidiano/ultimas-noticias/2019/05/07/witzel-e-denunciado-a-onupor-acoes-policiais-com-mortes-no-rio-de-janeiro.htm?cmpid= copiaecola\&cmpid=copiaecola

Saramago, J. (1999). La alternativa al neoliberalismo se llama conciencia. Recuperado de https://medium.com/cuadernoideol\%C3\%B3gico/la-alternativa-al-neoliberalismo-se-llama-conciencia-c86f44ddadf1

Schwartz, Y. (2012). Expérience et connaissance du travail. Paris : Les Éditions Sociales.

Sholz, T. (2016). Cooperativismo de plataforma. São Paulo: Editora Elefante.

Singer, P. (2008). Economia solidária (P. S. Oliveira, Entrevistador). Estudos Avançados, 22 (62), 288-314.

Standing, G. (2011). The precariat: the dangerous new class. New York: Bloomsbury Academic.

Trinquet, P. (2010). Trabalho e educação: o método ergológico. Revista HISTEDBR On-line, 10(38), 93-113.

Wisner, A. (1994). A inteligência no trabalho: textos selecionados de ergonomia. São Paulo: Fundacentro.

\section{Endereço para correspondência}

jinga@uol.com.br
Recebido em: 5/11/2019

Revisado em: 21/7/2020

Aprovado em: 5/8/2020 